\title{
A revolução tropicalista e a axiomática capitalista
}

\author{
LUIS FERNANDO DE CARVALHO SOUSA ${ }^{1}$
}

A tropicália foi um movimento cultural brasileiro do final da década de 1960 que despontou como revolução cultural, sinalizando para novas formas de se pensar a realidade vinculada à produção cultural. Seu caráter revolucionário deu-se pela forte contestação social da realidade brasileira e sua aspiração pela mudança dos paradigmas sociais vividos naquele período. É mister salientar que a tropicália produziu cultura nos mais diferentes ramos. Na música, Gilberto Gil e Caetano Veloso despontam como expoentes; nas artes plásticas, têm-se as obras de Hélio Oiticica; no cinema, Glauber Rocha e, no teatro, José Celso Martinez (FAVARETTO, 200o). Entretanto, nessa exposição, trataremos somente do aspecto musical.

A produção cultural dos anos 6o é muito variada. Diversos grupos e estilos surgiram; contudo, nenhum deles questionava ou tentava romper a lógica do sistema capitalista. A Jovem Guarda, por exemplo, era considerada alienada e reprodutora do modelo de vida capitalista estadunidense em terras brasileiras (HOLLANDA; GONÇALVES, 1982); já o movimento tropicalista era retratado de outra maneira.

Na opção tropicalista o foco da preocupação política foi deslocado da área da Revolução Social para o eixo da rebeldia, da intervenção localizada, da política concebida enquanto problemática cotidiana, ligada à vida, ao corpo, ao desejo à cultura em sentido amplo (HOLLANDA; GONÇALVES, 1982, p.66).

Partindo dessa premissa exposta por Hollanda \& Gonçalves, o movimento tropicalista conseguiu produzir cultura, questionando os valores da sociedade vigente e apontando para novos modos de vida e mecanismos interpeladores do sistema. Entendendo que a história humana é definida pela produção através de rupturas e reinvenções de sistemas e estruturas (culturais, sociais, econômicas e políticas) marcadas pelas contingências históricas ${ }^{2}$, o movimento tropicalista descodificou os fluxos culturais por meio de uma nova maneira de produção de desejos; nova maneira de ser e conceber a cultura. A novidade cultural da tropicália apontada por Favaretto (200o) destoava de tudo o que se havia produzido até o período, sendo, inclusive, difícil de ser classificada pelos críticos musicais e outras frentes que faziam sucesso, como a MPB e a Bossa Nova, que "de pronto" foram facilmente classificadas como

\footnotetext{
${ }^{1}$ Possui graduação em Teologia pela Universidade Metodista de São Paulo(2011) e graduação em História pelo Centro Universitário de Barra Mansa(2007). E-mail: luisffilo@hotmail.com

${ }^{2}$ Uma das formas de produção do desejo pontuadas por Deleuze e Guattari é explicitada em Mil Platôs, Vol. 1 (1995), em que os autores descrevem os movimentos de desterritorialização e reterritorialização como elementos que engendram a produção dos desejos e rupturas com antigas formas de representação. Nesse sentido, também sinalizam, em O Anti-Édipo (2010), para a história humana, como a história das produções (paixões, desejos, modos de existência, etc.), que é fortemente marcada pelas contingências e clivagem de sistemas antigos com insurgentes.
} 
músicas populares. Por ter descodificado os fluxos culturais do período e ter trazido uma inovação na produção dos desejos artísticos, "foi suficiente para confundir os critérios reconhecidos pelo público e sancionados por festivais e pela crítica" (FAVARETTO, 2000, p.20).

O que a sociedade não notava é que, na produção do movimento tropicalista, operava o movimento de desterritorialização e reterritorialização da cultura, produzindo sua forma de ser e opondo-se ao modelo musical dominante do período. Deleuze e Guattari questionam: "Como é possível que os movimentos de desterritorialização e os processos de reterritorialização não fossem relativos, não estivessem em perpétua ramificação, presos uns aos outros?” (DELEUZE; GUATTARI, 200o, p.17). Os filósofos franceses apontam para a concomitância dos movimentos que operam quando se consegue produzir novas formas sociais e culturais, rompendo com aquilo que fora estabelecido como paradigma. Era o que ocorria, a tropicália construía sua identidade ocupando espaços dentro do cenário social brasileiro.

O tropicalismo evidenciou o tema do encontro cultural e o conflito das interpretações, sem apresentar um projeto definido de superação; expôs as indeterminações do país, no nível da história e das linguagens, devorando-as; reinterpretou em termos primitivos os mitos da cultura urbano-industrial, misturando e confundindo seus elementos arcaicos e modernos, explícitos ou recalcados, evidenciando os limites das interpretações em curso (FAVARETTO, 2000, p.55-56).

A possibilidade dessa criação e da emergência de uma nova cultura só se efetuou por causa da natureza do sistema capitalista, uma vez que é inerente ao próprio capitalismo a propiciação da descodificação dos fluxos, a desterritorialização e a reterritorialização. Pelo fato de descodificar os fluxos, o capitalismo permite a liberação dos "fluxos do desejo num campo desterritorializado" (DELEUZE; GUATTARRI, 2010, p.52). Tal descodificação dos fluxos culturais produzida pelo movimento tropicalista criou espaços num campo brasileiro que não comportava mais somente os cantores populares e se encontrava no desejo de uma juventude ávida por mudanças. O espaço antes ocupado pela música popular passava por transformações e cedia espaço para outra forma, denominada música tropicalista.

Em o Anti-Édipo, o esforço dos autores é mostrar como o sistema capitalista, ao mesmo tempo em que permite que os fluxos descodificados fluam no interior do socius, tenta o tempo todo capturá-los, axiomatizando-os e fazendo que esses corroborem para a produção de lucro. Por esse motivo, faz-se sua crítica, pois atua como um grande capturador das formas de produção (social, cultural, artística). Embora possibilite a descodificação de fluxos e produção de novas formas de vida, o capitalismo tende a encerrá-las dentro de suas trincheiras: "o que ele descodifica com uma das mãos, axiomatiza com a outra” (DELEUZE; GUATTARI, 2010, p.326). Portanto, as produções que sinalizam para o questionamento e ruptura com o sistema 
capitalista tendem a ser, rapidamente, integradas e cooptadas por ele. Como afirmam os autores:

[...] num regime como este, é impossível distinguir, mesmo que em dois tempos, a descodificação e a axiomatização que vêm substituir os códigos desaparecidos. É ao mesmo tempo que os fluxos são descodificados e axiomatizados pelo capitalismo (DELEUZE; GUATTARI, 2010, p.326-327).

Nesse sentido, pode-se observar que, ainda que haja a tentativa de romper com o modus operandi do capitalismo, o movimento de captura e axiomatização aparecem colocando essa tentativa a favor da produção. Qual foi a ruptura cultural sinalizada pelo movimento tropicalista? O movimento tropicalista rompia com a forma popular de caráter burguês personificada pela Bossa Nova, por exemplo, que se adequava ao way of life do homem urbano brasileiro (CASTRO, 1998), coadunando e corroborando com o sistema capitalista à medida que fazia afluir os fluxos culturais para o sistema de produção, alimentando, dessa maneira, não somente a formatação burguesa de cultura, como a manutenção do sistema por meio da produção voltada para o consumo e para o lucro.

A tropicália operou como uma espécie de descodificação dos fluxos de produção cultural do período dos anos 6o, quando impingiu uma nova forma de concepção de universo "para além" da dicotomização esquerda-direita que se fazia no período (GORENDER, 1986), produzindo algo próprio, num movimento cultural ímpar, que pode ser classificado como descodificação dos fluxos culturais, pois escapava do que era, até o período, conhecido e concebido como cultura, reforçando a tese de produção desejante”, uma vez que "O desejo é esse conjunto de sínteses passivas que maquinam os objetos parciais, os fluxos e os corpos, e que funcionam como unidades de produção" (DELEUZE; GUATTARI, 2010, p. 43). Essa produção, sobretudo por meio de sua estética, questionava a mentalidade burguesa nacional, articulando-se com os desejos de grupos que não eram contemplados por nenhum modelo. A tropicália conseguia produzir "[...] a alternância entre afirmação do desejo como forma de burlar a repressão e sua degradação irônica, carnavalizando a música [...]" (FAVARETTO, 2000, p.101) através de uma estética que rompia com os padrões burgueses.

É inegável que a tropicália: 1) descodificou os fluxos culturais do final da década de $1960 ; 2)$ desterritorializou e reterritorializou um espaço significativo no universo

\footnotetext{
3 Para Deleuze e Guattari o desejo é caracterizado pela proatividade, ou seja, sempre concebido como algo positivo e não como ausência, como, por exemplo, defende a perspectiva freudiana. Nesse sentido, o inconsciente é tido como um fértil campo em que as produções se dão e objetivam-se no real; na imanência. O ser humano é concebido pelos filósofos franceses como holístico, isto é, integrado ao cosmos, sendo capaz de produzir e expressar seus desejos a partir da interação com o mundo em que vive. A produção, portanto, é uma das essências do humano que procura expressar-se produzindo sempre (DELEUZE; GUATTARI, 2010).
} 
artístico; 3) formatou uma nova maneira de expressão e produção cultural. Tais pontos são relevantes para se pensar meios de questionamento e superação da máquina capitalista, pois se apresentam como alternativas. Entretanto, por que não são suficientes para a criação de novas formas de vida revolucionária? A explicação é simples. O movimento, assim como outras tantas maneiras que se apresentaram como revolucionárias, foi axiomatizado.

A axiomática capitalista se processa fazendo que os fluxos, inicialmente descodificados, passem a operar a favor da produção. Nesse sentido, a própria produção voltada para o mercado fonográfico sinaliza para tal processo. Enquanto movimento cultural de contestação e produção de desejo, a tropicália cumpriu seu papel, mas, assim como apontam Deleuze e Guattari, quando fazem o balanço de maio de 68 , houve a traição dos desejos revolucionários, uma vez que se optou por integrar o sistema capitalista (DELEUZE; GUATTARI, 2002).

A exemplo do movimento de 1968, a tropicália despontou como modo revolucionário de existência, mas, com o passar dos anos, disputava o mercado de produção fonográfica com outros grupos da música popular brasileira, operando, assim, a favor do sistema capitalista. Na análise de Favaretto sobre a axiomatização da tropicália, o autor ressalta que:

Sendo esvaziada sua pretensão de violentar as convenções, a novidade de linguagem é normatizada e consumida: aquilo que realmente tem interesse estético é consumido apenas como extravagância. É o que ocorre com os choques: selecionados e diluídos pelo mercado, são transformados em meros excitantes (FAVARETTO, 2000, p.139).

Com sua adesão ao mercado fonográfico, a tropicália passava, então, de movimento musical-estético revolucionário a mais um elemento do consumo da sociedade capitalista, despertando a reação do público que se identificava com a forma revolucionária como havia surgido no cenário musical brasileiro. "Comprometido com a participação política dos artistas, o público a que se dirigia o trabalho dos tropicalistas repudiou-lhes a postura, tachando-a de reacionária e considerando-a como uma agressão [...]” (FAVARETTO, 200o, p. 141). Assim, aos poucos, mais um movimento revolucionário era diluído no sistema capitalista.

O capitalismo se processa "numa axiomática mundial que opõe sempre novos limites interiores à potência revolucionária dos fluxos descodificados" (DELEUZE; GUATTARI, 2010, p. 326) e, nesse sentido, a produção efetuada pelo tropicalismo operou a favor do mercado capitalista. Os desejos revolucionários e as contestações da tropicália passaram a ser consumidos como objetos de desejo dos que se identificavam com a proposta e se sentiam representados pelo movimento (HOLLANDA; GONÇALVES, 1982). Dessa maneira, repetiram a história das revoluções descritas por Deleuze e Guattari como "traição dos desejos das massas". 
(DELEUZE; GUATTARI, 2002, p.268).

A crítica descrita por Deleuze e Guattari em O Anti-Édipo consiste em afirmar que o sistema capitalista tende a axiomatizar os fluxos descodificados e as tendências revolucionárias, fazendo-as operar a favor da produção capitalista. Isso pode ser aplicado também ao movimento tropicalista, uma vez que sua inicial contestação e forma revolucionária, estética e musical acabam por operar e integrar o mercado de consumo. Assim, não se manteve a dinâmica e ímpeto revolucionários. A axiomática operou de maneira a fazer que os fluxos descodificados fossem colocados em função do lucro e da manutenção do sistema, que é caracterizado por sempre conseguir alargar seus limites de produção (DELEUZE; GUATTARI, 2010).

\section{Referências}

CASTRO, Ruy. Chega de saudade: a história e as histórias da Bossa Nova. São Paulo: Companhia das Letras, 1998.

DELEUZE, Gilles; GUATTARI, Félix. A ilha deserta e outros textos: textos e entrevistas (1953-1974). São Paulo: Iluminuras, 2002.

. O anti-Édipo: capitalismo e esquizofrenia. São Paulo: Ed. 34, 2010.

. Mil Platôs: capitalismo e esquizofrenia. Vol.1. Rio de Janeiro: Editora 34,

1995 .

FAVARETTO, Celso. Tropicália, alegoria, alegria. São Paulo: Ateliê Editorial, 1996.

GORENDER, Jacob. Combate nas trevas. A esquerda brasileira: das ilusões perdidas à luta armada. São Paulo: Ática, 1986.

HOLLANDA, Heloísa Buarque de; GONÇALVES, Marcos A. Cultura e participação nos anos 6o. São Paulo: Brasiliense, 1982.

Submissão: 24.04.2017 / Aceite: 12.05.2017 